\title{
Effets des tourteaux de graines décortiquées du cultivar bebu de Citrullus lanatus et de Lagenaria sicerari a sur les performances de croissance du poulet de chair
}

\author{
Abdourhamane Ibrahim TOURE ${ }^{1 *}$, Gilbert Comlan Zougou TOVIGNON ${ }^{1}$, \\ Arsène Valery MBOKO ${ }^{1}$, Moussa KIMSE ${ }^{3}$, Férence Ndzani MATUMUINI ${ }^{1}$, \\ Tra Bi Serge DOUBI ${ }^{3}$, Hippolyte Hermann $\mathrm{TRO}^{3}$, Bi Irié Arsène ZORO ${ }^{3}$ et \\ Benoit BOUKILA $^{1}$
}

\author{
${ }^{1}$ Institut National Supérieur d'Agronomie et de Biotechnologies (INSAB), Université des Sciences et \\ Techniques de Masuku (USTM), B.P. 941 Franceville, Gabon. \\ ${ }^{2}$ Laboratoire de Biochimie de la Faculté des Sciences de l'Université des Sciences et Techniques de Masuku \\ (USTM), B.P. 901 Franceville, Gabon. \\ ${ }^{3}$ Unité de Formation et de Recherche (UFR) : Sciences de la Nature, Université Nangui Abrogoua, B.P. 801 \\ Abidjan, Côte d'Ivoire. \\ *Auteur correspondant ; E-mail: aitoure@yahoo.fr
}

Received: 24-02-2021

Accepted: $24-08-2021$

Published: 31-08-2021

\section{RESUME}

La valorisation des ressources phytogénétiques non conventionnelles pour l'amélioration de la qualité des aliments pour animaux a motivé cette recherche. L'étude menée à la ferme et aux Laboratoires de Génétique et de Biochimie de l'Université Nangui Abrogoua, à Abidjan, en Côte d'Ivoire, a été réalisée dans le but d'évaluer les effets des tourteaux de graines de Citrullus lanatus et de Lagenaria siceraria sur les performances de croissance du poulet de chair, pendant 42 jours. Pour la réalisation de cet essai, les poussins ont été répartis au hasard dans sept box à raison de 40 sujets correspondant chacun à un aliment (BT0; $\mathrm{BT} 1 \mathrm{Cl}(10 \%)$; $\mathrm{BT} 2 \mathrm{Cl}$ (20\%) ; BT3Cl (30\%) ; BT1Ls (10\%) ; BT2Ls (20\%) ; BT3Ls (30\%)). La pesée des différentes rations servies et des refus se faisait avant toute nouvelle distribution, pour l'évaluation de l'ingestion. Les animaux ont été pesés périodiquement pour la détermination de leur croissance journalière. Il ressort des résultats que, quel que soit l'âge, le poids des animaux nourris à la ration témoin a été plus élevée que ceux enregistrés au niveau des sujets soumis aux rations contenant les tourteaux de cucurbites. Il varie de 1127,77 $\pm 3,45 \mathrm{~g}$ à 748,75 $\pm 1,25 \mathrm{~g}$ avec l'aliment témoin ; de 455,12 $\pm 2,19$ à 177,50 $\pm 1,50 \mathrm{~g}$ avec l'aliment contenant Citrullus lanatus (bebu) et de 470,51 $\pm 2,49$ à 275,00 $\pm 1,61 \mathrm{~g}$ avec l'aliment contenant Lagenaria siceraria. Le GMQ est plus élevé chez les sujets alimentés à la ration témoin que chez ceux ayant reçu les cucurbites dans leurs rations ; il varie de 84,52 $\pm 1,04 \mathrm{~g} / \mathrm{j}$ à $62,38 \pm 0,45 \mathrm{~g} / \mathrm{j}$ avec l'aliment témoin ; de 28,57 $\pm 0,35 \mathrm{à} 8,81 \pm 0,16 \mathrm{~g} / \mathrm{j}$ avec l'aliment contenant Citrullus lanatus (bebu) et de 22,86 $\pm 0,24 a ̀$ 9,76 $\pm 0,18 \mathrm{~g} / \mathrm{j}$ avec l'aliment contenant Lagenaria siceraria. Par ailleurs, les IC les plus intéressants ont été obtenus chez les sujets soumis aux rations contenant les cucurbites ; il varie de $1,78 \pm 0,01$ à $0,35 \pm 0,01$ avec la ration contenant Citrullus lanatus (bebu); de 1,83 $\pm 0,00$ à $0,68 \pm$ 0,01 avec l'aliment contenant Lagenaria siceraria et de 4,44 $\pm 0,01$ à $1,47 \pm 0,02$ avec l'aliment témoin. 
S'agissant des paramètres biochimiques du sang, à l'exception de l'acide urique qui a été plus élevé chez les sujets alimentés à la ration témoin par rapport à celui des animaux soumis aux rations contenant les cucurbites, ceux des animaux nourris à la ration témoin ont été comparables à ceux des sujets soumis aux rations contenant les cucurbites.

(C) 2021 International Formulae Group. All rights reserved.

Mots clés : Cucurbites, rations, tourteaux, performances de croissance, poulet de chair.

\title{
Effects of shelled seed cake of bebu cultivar from Citrullus lanatus and Lagenaria siceraria on broiler chicken growth performance
}

\begin{abstract}
The valuation of unconventional plant genetic resources for improving the quality of animal feed motivated this research. The study was conducted on the farm and at the Genetics and Biochemistry Laboratories of Nangui Abrogoua University in Abidjan, Côte d'Ivoire. This study was conducted to assess the effects of Citrullus lanatus and Lagenaria siceraria seed meal on broiler chicken growth performance for 42 days. For the purpose of this test, chicks were randomly assigned to seven boxes with 40 subjects each corresponding to a food (BT0; BT1Cl (10\%); BT2Cl (20\%); BT3Cl (30\%); BT1Ls (10\%); BT2Ls (20\%); BT3Ls (30\%)). The weighing of the different rations served and refusals was done before any new distribution, for the evaluation of the ingestion. The animals were weighed periodically to determine their daily growth. The results show that, whatever the age, the feed consumption of the animals fed to the control diet was higher than that recorded for the subjects subjected to rations containing cucurbites; it varies from $1127.77 \pm 3.45$ to $748.75 \pm 1.25 \mathrm{~g}$ with the control feed; $455.12 \pm 2.19$ to $177.50 \pm 1.50 \mathrm{~g}$ with the feed containing Citrullus lanatus (bebu) and $470.51 \pm 2.49$ to $275.00 \pm 1.61 \mathrm{~g}$ with the feed containing Lagenaria siceraria. The GMQ is higher in subjects fed the control diet than in those fed the cucurbites in their diets; it varies from $84.52 \pm 1.04$ to $62.38 \pm 0.45 \mathrm{~g}$ with the control feed; from $28.57 \pm 0.35$ to $8.81 \pm 0.16 \mathrm{~g}$ with the food containing Citrullus lanatus (bebu) and from $22.86 \pm 0.24$ to $9.76 \pm 0.18 \mathrm{~g}$ with the fo od containing Lagenaria siceraria. Moreover, the most interesting IC were obtained in the subjects subjected to the rations containing the cucurbites; it varies from $1.78 \pm 0.01$ to $0.35 \pm 0.01$ with the ration containing Citrullus lanatus (bebu); from $1.83 \pm 0.00$ to $0.68 \pm 0.01$ with the food containing Lagenaria siceraria and $4.44 \pm 0.01$ to $1.47 \pm 0.02$ with the control food. For biochemical parameters of blood, with the exception of uric acid, which was higher in subjects fed the control diet than in animals fed cucurbite-containing diets, those of animals fed with the control diet were comparable to those of subjects fed with cucurbitecontaining diets.
\end{abstract}

(C) 2021 International Formulae Group. All rights reserved.

Keywords: Cucurbites, rations, meal, growth performance, broiler chicken.

\section{INTRODUCTION}

Le problème de sécurité alimentaire est un défi à relever dans la plupart des pays en développement. L'explosion démographique observée ces dernières années dans ces pays ayant pour corollaire une demande de plus en plus croissante en protéines d'origine animale justifierait cet état de chose (Niba et al., 2012). S'il est vrai que, l'élevage du gros bétail contribue pour un fort taux des approvisionnements en protéines animales dans de nombreux pays, les petites espèces comme la volaille, les cobayes, les lapins entre autres qui, sont à la portée de la majorité des ménages démunis, pourraient résoudre le problème de carence en protéines animales (Molina-Flores et al., 2020). Le poulet peut constituer un revenu non négligeable pour les populations africaines (Bouafou et al., 2011). Par ailleurs, en aviculture, la satisfaction des besoins des animaux en éléments nutritifs et, particulièrement en protéines constitue la composante la plus importante du coût de 
production, soit 65 et $75 \%$ respectivement chez les poulets de chair et les pondeuses (Oyelola et al., 2004; Jha et Misra, 2021). Il a été démontré que la présence des sources protéiniques dans l'alimentation des animaux pourrait doubler ou tripler leur productivité. Cependant, Mariotti et Gardner (2019) estimaient déjà que les sources traditionnelles de protéines végétales devaient non seulement devenir plus onéreuses mais, vont aussi se raréfier dans un futur assez proche d'où, la nécessité de concentrer les efforts sur la recherche des sources de protéines disponibles localement comme les Cucurbitaceae. Ce sont des plantes dicotylédones comportant plus de 800 espèces réparties en 120 genres (Rahman, 2013). Plusieurs auteurs ont montré que les Cucurbitaceae de type "pistaches" ont une grande valeur nutritionnelle (Loukou et al., 2007; Syed et al., 2019). Les Cucurbitaceae oléagineuses contiennent essentiellement les protides dont le total est compris entre 24,3 41,6\% MS, les lipides entre 42,9 - 57,3\% MS et le calcium entre 129,7-269,7 mg / 100 MS (Steiner et al., 2014). Par ailleurs, leurs teneurs en protéines sont presque identiques à celles du soja (42-45\% MS) mais, supérieures à celles de l'arachide (23\%MS).

L'objectif de ce travail est d'étudier l'incidence du niveau d'incorporation des cucurbites sur les perfor mances de croissance chez le poulet de chair.

\section{MATERIEL ET METHODES}

\section{Zone d'étude}

L'étude s'est déroulée entre février et août 2013 au Laboratoire de Génétique et de Biochimie de l'Université Nangui Abrogoua, à Abidjan, en Côte d'Ivoire. Cette zone est située entre $5^{\circ} 29^{\prime} 54,4^{\prime \prime}-5^{\circ} 29^{\prime} 54,6^{\prime \prime}$ de latitude Nord et entre $4^{\circ} 03^{\prime} 52,7^{\prime}$ '- $4^{\circ} 03^{\prime} 53,9^{\prime}$ 'de longitude Ouest. On y distingue quatre saisons dont, deux saisons pluvieuses et deux saisons sèches (Sodexam, 2015). La température moyenne varie entre $24 \pm 0,8$ et $28 \pm 0,7^{\circ} \mathrm{C}$ et les mois les plus chauds sont ceux de février, de mars et d'avril avec $28,04 \pm 0,7{ }^{\circ} \mathrm{C} ; 28,08 \pm 0,7{ }^{\circ} \mathrm{C}$ et $27,36 \pm 0,8{ }^{\circ} \mathrm{C}$, respectivement (Sodexam, 2015). Cette zone est fortement humide avec des taux allant de $82,75 \pm 2,6$ à $94,7 \pm 1,7 \%$. La végétation est composée d'une portion de la forêt ombrophile, de jachères de différents âges et d'une vaste pelouse; sur un sol sabloargileux qui se prête assez bien à la culture de Lagenaria siceraria et de Citrullus lanatus.

\section{Matériel}

\section{Matériel animal}

Pour la réalisation de cet essai, 280 poussins de chair, de souche Hubbard, ont été utilisés lors de la phase de démarrage et pendant la phase de croissance - finition, ces 280 sujets ont été répartis au hasard dans sept box à raison de 40 sujets / box.

\section{Matières premières pour la fabrication de l'aliment}

Elles sont composées de grains de maïs, de tourteaux de soja, de son de blé, de coquillage, de différents sels (chlorure de sodium, phosphate bicalcique), et de tourteaux de graines décortiquées de Cucurbitaceae oléagineuses (cultivar bebu de Citrullus lanatus et de Lagenaria siceraria).

\section{Logement}

Durant cet essai, les animaux ont été placés dans un bâtiment mesurant $11 \mathrm{~m}$ de longueur; $10 \mathrm{~m}$ de largeur et $3,5 \mathrm{~m}$ de hauteur, compartimenté en 16 box d'élevage de cinq mètres carrés chacun et un box supplémentaire de $30 \mathrm{~m}^{2}$ servant de lieu de stockage d'aliments et de matériels d'élevage. Ces box d'élevage sont munis chacun de mangeoires et d'abreuvoirs, à raison d'un abreuvoir de 5 litres / 40 sujets au démarrage puis deux abreuvoirs de 15 litres / box d'élevage en phase de croissance-finition; et une mangeoire de 5 litres / 40 sujets au premier âge et deux mangeoires de 20 litres / box au deuxième âge. En outre, deux éleveuses artificielles et une quantité de copeau de bois (environ $4 \mathrm{~kg} / \mathrm{m}^{2}$ ) ont été utilisées, avec 
environ $10 \mathrm{~cm}$ d'épaisseur dans chaque box d'élevage. Des produits vétérinaires (complexes vitaminiques AD3EK, vaccins, antiparasitaires), de l'eau minérale (OLGANE) et un pulvérisateur ont été nécessaires à la vaccination.

\section{Matériel végétal}

Il était constitué de graines des Cucurbitaceae oléagineuses du cultivar bebu de $C$. lanatus et de $L$. siceraria. Après l'achat dans les marchés locaux d'Abidjan, ces graines ont été décortiquées, torréfiées à $80^{\circ} \mathrm{C}$ pendant dix minutes puis broyées grâce à un moulin de commerce. Cette dernière phase est suivie d'extraction de l'huile avant l'obtention de tourteaux.

\section{Formulation des aliments}

Les ingrédients entrant dans la formulation de la ration ont été achetés chez les revendeurs des produits et sous-produits agricoles de la ville d'Abidjan. La formulation a été faite sur la base des recommandations de Araujo et al. (2004) ; Thornton (2010) et Brah et al. (2015). Le broyage et le mélange des intrants ont été effectués à l'aide d'un broyeurmélangeur de commerce de capacité une tonne. Un échantillon de $100 \mathrm{~g}$ de chaque ration expérimentale a été prélevé et séché à $60^{\circ} \mathrm{C}$ jusqu'à poids constant dans une étuve ventilée de marque Memmert. Les échantillons ont été broyés aux mailles de $2 \mathrm{~mm}$ à l'aide d'un broyeur TRAMONTINA TRE25 pour les analyses bromatologiques. La composition chimique des aliments expérimentaux est présentée dans le Tableau 1.

Sept rations ont été utilisées. La ration R0 était la ration du commerce et les rations RbCla10 ; RbCla20 ; RbCal30 ; RLsi10 ; RLsi20 et RLsi30 contenaient, respectivement $10 \% ; 20 \% ; 30 \%$ de bebu de Citrullus lanatus et $10 \% ; 20 \% ; 30 \%$ de Lagenaria siceraria. L'eau était distribuée à volonté.

Les rations expérimentales étaient constituées ainsi qu'il suit :

BT0 : ration de commerce
$\mathrm{BT} 1 \mathrm{Cl}$ : ration avec $10 \%$ de bebu de Citrullus lanatus

BT2Cl : ration avec 20\% de bebu de Citrullus lanatus

BT3Cl : ration avec $30 \%$ de bebu de Citrullus lanatus

BT1Ls: ration avec $10 \%$ de Lagenaria siceraria

BT2Ls: ration avec $20 \%$ de Lagenaria siceraria

BT3Ls: ration avec $30 \%$ de Lagenaria siceraria

\section{Conduite des essais et collecte des données}

Essai de croissance

La conduite de l'essai s'est faite en deux phases (Aviagen, 2018) : la phase de démarrage et la phase de croissance-finition.

Phase de démarrage: la période de démarrage va de l'arrivée des poussins d'un

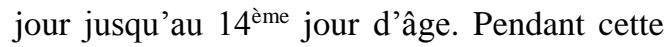
période les poussins ont été gardés sous radiant à gaz, au sol sur une litière constituée de copeaux de bois de $10 \mathrm{~cm}$ d'épaisseur environ. Les poussins ont été élevés jusqu'à deux semaines d'âge dans la poussinière, avec un dispositif d'élevage qui leur est adapté. Après évaluation de la mortalité durant le démarrage, les poussins vivants ont été répartis dans les box en fonction du type d'alimentation pour la seconde étape (phase de croissance-finition).

Phase de croissance-finition: à partir du $12^{\text {ème }}$ jour, le passage de l'aliment de démarrage à l'aliment de croissance, appelé transition alimentaire, a été observé. Cette transition consiste en une diminution progressive de l'aliment de démarrage et d'une augmentation de l'aliment de croissance pendant trois jours dans les proportions respectives de $75 / 25 \% ; 50 / 50 \%$ et $25 / 75 \%$.

Pendant la phase de croissance-finition, l'alimentation à base de tourteaux de graines décortiquées du cultivar bebu de C. lanatus et de L. siceraria a été utilisée. Les rations alimentaires et l'eau ont été distribuées deux fois par jour aux animaux entre $8 \mathrm{~h}$ et $9 \mathrm{~h}$ et entre $16 \mathrm{~h}$ et $17 \mathrm{~h}$. Les sujets ont été constitués 
en des lots homogènes et ont été suivis individuellement pendant 42 jours. Tout au long de l'essai, les anticoccidiens, les complexes vitaminiques et les vaccins ont été distribués et administrés selon le contexte épidémiologique dans l'élevage, le type de production, la durée d'élevage et l'état général du troupeau (Dawkins et al., 2004). Tous les matins, les refus alimentaires ont été récupérés matin et pesés. S'agissant des oiseaux, les prises de poids (à jeun le matin) ont été faites de façon hebdomadaire ; cette pesée a permis de déterminer l'indice de consommation de chaque animal. Toutes les pesées ont été effectuées à l'aide d'une balance digitale de capacité $5 \mathrm{~kg}$ et de précision $1 \mathrm{~g}$.

Evaluation des paramètres sanguins

Les prélèvements sanguins ont été effectués sur cinq poulets pris au hasard dans chaque lot à la fin de la phase croissancefinition ( $6^{\text {ème }}$ semaine d'élevage). Le prélèvement du sang a été effectué à jeun le matin, avant la distribution de l'aliment pour éviter la lipémie post-prandiale, c'est-à-dire l'augmentation de la charge en lipides sur les triglycérides circulants après le repas, qui se traduit par une opalescence du sang qui perturbe le dosage (Bölükbaşi et al., 2006). Pour ce faire, la zone de prélèvement a été désinfectée à l'alcool iodé à 10\% (Bétadine). Ensuite, une aiguille stérile a été introduite dans la veine alaire afin de recueillir le sang dans les tubes de $5 \mathrm{~mL}$ sous vide.

Analyses bromatologiques des rations expérimentales et du sang des sujets

Les analyses des échantillons des rations expérimentales ont été réalisées au Laboratoire de Génétique et de Biochimie de l'Université Nangui Abrogoua, à Abidjan, en Côte d'Ivoire. Elles ont servi à la détermination de leurs caractéristiques bromatologiques (humidité $(\%)$; matière sèche $(\%)$, protéines brutes $(\%)$; matières grasses $(\%)$; fibres $(\%)$; glucides (\%); cendres (\%) et $\mathrm{pH})$. Deux répétitions ont été nécessaires pour la détermination de la valeur moyenne de chacune de ces composantes. Les teneurs en matière sèche (MS) et en humidité ont été déterminées selon la méthode de l'AOAC (1990). Le taux de protéines brutes (PB) a été obtenu par la méthode de Kjeldhal (AOAC, 1990); celui des matières grasses (MG) par la méthode d'extraction sous reflux à l'aide de l'appareil de Soxhlet; les cendres ont été déterminées par incinération selon la méthode de l'AOAC (1990) ; les fibres ont été réalisées par la méthode de Sheerer (Dorée, 1999). S'agissant du $\mathrm{pH}$, il a été déterminé à l'aide d'un pHmètre. Par ailleurs, les dosages des paramètres sanguins tels que les taux de glucose (glycémie), de protéines (protéinémie), d'acide urique (uricémie), de créatinine (créatininémie), de cholestérol (cholestérolémie), de triglycérides (triglycéridémie) ont été effectués à l'aide de l'analyseur Hitachi, Roch 902, Japon.

\section{Analyses statistiques}

Les données obtenues ont été soumises à l'analyse de variance à 2 facteurs (taux d'incorporation: 10,20 et $30 \%$ » et « cultivars: $C$. lanatus et $L$. siceraria) qui a permis d'étudier l'effet individuel ou combiné de ces deux facteurs en vue de comparer les moyennes issues des aliments formulés qui ont servi à nourrir les poulets de chair. La significativité du test a été déterminée en comparant la probabilité $P$ associée à la statistique du test de Fischer-Snedecor au seuil théorique de $\alpha=0,05$. Lorsqu'il y a une différence significative $(p<0,05)$, alors le test de Dunnett a été réalisé afin d'identifier le ou les traitements des graines qui diffèrent significativement du traitement témoin. Tous ces calculs ont été effectués grâce au logiciel statistique Statistica 7.1. 
Tableau 1 : Formulation et composition chimique des rations expérimentales.

\begin{tabular}{|c|c|c|c|c|c|c|c|}
\hline \multirow{3}{*}{ Matière première } & \multirow{3}{*}{$\begin{array}{c}\text { BT0 } \\
\text { (commerce) }\end{array}$} & \multicolumn{3}{|c|}{ Cultivar bebu de Citrullus } & \multirow{2}{*}{\multicolumn{3}{|c|}{ Lagenaria siceraria }} \\
\hline & & & lanatus & & & & \\
\hline & & $\begin{array}{l}\text { BT1Cl } \\
(10 \%)\end{array}$ & $\begin{array}{l}\text { BT2Cl } \\
(20 \%)\end{array}$ & $\begin{array}{l}\text { BT3Cl } \\
(30 \%)\end{array}$ & $\begin{array}{l}\text { BT1Ls } \\
(10 \%)\end{array}$ & $\begin{array}{l}\text { BT2Ls } \\
(20 \%)\end{array}$ & $\begin{array}{l}\text { BT3Ls } \\
(30 \%)\end{array}$ \\
\hline Maïs grain (type INRA 82) (\%) & ND & 67,7 & 62,7 & 57,7 & 67,7 & 62,7 & 57,7 \\
\hline Citrullus lanatus (tourteau)(\%) & ND & 10,0 & 20,0 & 30,0 & - & - & - \\
\hline Lagenaria siceraria (tourteau) (\%) & ND & - & - & - & 10,0 & 20,0 & 30,0 \\
\hline Son de blé (INRA 104) (\%) & ND & 20,0 & 15,0 & 10,0 & 20,0 & 15,0 & 10,0 \\
\hline Sel $(\mathrm{NaCl})(\%)$ & ND & 0,25 & 0,25 & 0,25 & 0,25 & 0,25 & 0,25 \\
\hline Coquillage (\%) & ND & 2,00 & 2,00 & 2,00 & 2,00 & 2,00 & 2,00 \\
\hline $\operatorname{Mycofix}(\%)$ & ND & 0,10 & 0,10 & 0,10 & 0,10 & 0,10 & 0,10 \\
\hline \multicolumn{8}{|c|}{ Composition biochimique analysée } \\
\hline Humidité \% & 11,2 & 11,1 & 11,8 & 11,6 & 11,7 & 11,5 & 11,2 \\
\hline Matière sèche $\%$ & 88,8 & 88,9 & 88,2 & 88,4 & 88,3 & 88,5 & 88,8 \\
\hline Cendres \% & 4,62 & 2,83 & 2,99 & 4,10 & 3,85 & 3,74 & 4,43 \\
\hline Fibres $\%$ & 7,62 & 9,19 & 11,0 & 11,2 & 8,77 & 11,4 & 11,6 \\
\hline Lipides \% & 9,03 & 9,16 & 8,67 & 8,93 & 8,35 & 9,28 & 11,6 \\
\hline Protéines \% & 20,4 & 12,5 & 18,1 & 19,7 & 17,2 & 21,5 & 24,4 \\
\hline Glucides \% & 58,3 & 66,4 & 59,3 & 56,1 & 61,8 & 54,1 & 48,0 \\
\hline $\mathrm{pH}$ & 6,88 & 6,05 & 5,94 & 5,10 & 6,21 & 5,88 & 5,47 \\
\hline \multicolumn{8}{|c|}{ Valeurs calculées avec WUFFDA } \\
\hline EM (Kcal/Kg d'aliment) & 3050 & 3011 & 3081 & 3066 & 3008 & 3019 & 3011 \\
\hline Lysine (\%) & 1,21 & 0,41 & 0,41 & 0,55 & 0,57 & 0,58 & 0,67 \\
\hline Méthionine (\%) & 0,57 & 1,21 & 1,35 & 1,49 & 1,09 & 1,18 & 1,21 \\
\hline Méthionine + Cystine (\%) & 0,89 & 0,52 & 0,69 & 0,84 & 0,66 & 0,71 & 0,94 \\
\hline Calcium (\%) & 1,27 & 1,05 & 1,19 & 1,22 & 1,06 & 1,01 & 1,13 \\
\hline Phosphore Total & 0,24 & 0,13 & 0,29 & 0,35 & 0,48 & 0,51 & 0,29 \\
\hline
\end{tabular}

ND : non déterminé ; BT0 : Aliment témoin (de commerce) ; rations BT1Cl, BT2Cl, BT3Cl, BT1Ls, BT2Ls et BT3Ls: taux d'incorporation de $10 \%, 20 \%, 30 \%$ de bebu de Citrullus lanatus et 10\%, 20\%, 30\% de Lagenaria siceraria ; respectivement. 


\section{RESULTATS}

Effets du tourteau des graines décortiquées du cultivar bebu de Citrullus lanatus et de Lagenaria siceraria sur les performances de croissance chez le poulet de chair

Effets du tourteau des graines décortiquées du cultivar bebu de Citrullus lanatus et de Lagenaria siceraria sur la consommation alimentaire des poulets de chair

L'analyse du Tableau 2 révèle que, quel que soit l'âge, la consommation alimentaire a été influencée de façon significative par la présence des tourteaux de cucurbites dans les rations. Cependant, cette consommation a toujours été plus importante chez les sujets soumis à l'aliment témoin que celle enregistrée chez les animaux nourris aux aliments contenant les cucurbites. En effet, à la première, à la deuxième et à la troisième semaine, les consommations les plus élevées, ont été enregistrées chez les sujets nourris à la ration témoin, respectivement $749 \pm 1,25 ; 865$ $\pm 2,38$ et $1128 \pm 3,45$; et les plus faibles chez ceux soumis à la ration contenant 30\% Citrullus lanatus (bebu), respectivement $178 \pm$ $1,50 \mathrm{~g} ; 250 \pm 1,31 \mathrm{~g}$ et $283 \pm 1,28 \mathrm{~g}$. Par ailleurs, à la quatrième semaine, la consommation la plus élevée a été obtenue chez les animaux consommant la ration témoin $(1107 \pm 2,29 \mathrm{~g})$ et la plus faible chez ceux alimentés à la ration contenant $10 \%$ de Citrullus lanatus (bebu) $(430 \pm 1,34)$.

Effets du tourteau des graines décortiquées du cultivar bebu de Citrullus lanatus et de Lagenaria siceraria sur le poids vif (PV) des poulets de chair

Il ressort de la Figure 1 que, quelle que soit la ration, les poids des poulets ont été croissants du $14^{\text {ème }}$ au $42^{\text {ème }}$ jour. En effet, l'aliment témoin (BT0) a permis une croissance progressive et importante des poulets : de $410 \mathrm{~g}$ à environ $1000 \mathrm{~g}$ en une semaine puis de $1000 \mathrm{~g}$ à environ $1500 \mathrm{~g} \mathrm{du}$ $21^{\text {ème }}$ au $28^{\text {ème }}$ jour ; soit pratiquement un gain de poids d'environ $500 \mathrm{~g}$ hebdomadairement. Cependant, au niveau de tous les traitements à base de Cucurbitaceae, les animaux ont eu des poids variant de de $410 \mathrm{~g}$ à moins de $1000 \mathrm{~g} \mathrm{du}$ $14^{\text {ème }}$ au $42^{\text {ème }}$ jour d'élevage. Ainsi, au $42^{\text {ème }}$ jour (fin de l'essai), les poids les plus importants avec les Cucurbitaceae incorporées ont été obtenus avec respectivement $10 \%$ de bebu de C. lanatus $(917 \pm 17,8 \mathrm{~g}), 20 \%$ de $L$. siceraria $(916 \pm 23,1 \mathrm{~g}), 10 \%$ bebu $(903 \pm 17,2$ g), $20 \%$ de bebu $(887 \pm 13,7 \mathrm{~g}) 30 \%$ de $L$. siceraria ( $884 \pm 18,6 \mathrm{~g}$ ) et, enfin $30 \%$ de bebu $(857 \pm 14,8 \mathrm{~g})$.

Effets du tourteau des graines décortiquées du cultivar bebu de Citrullus lanatus et de Lagenaria siceraria sur le gain moyen quotidien (GMQ) des poulets de chair

Du Tableau 3, il ressort que, quel que soit l'âge, les GMQ des poulets ont été influencés de façon significative par la présence des tourteaux de cucurbites dans les rations. Cependant, ces GMQ ont été plus importants chez les sujets nourris à l'aliment témoin que ceux enregistrés chez les animaux soumis aux aliments contenant les cucurbites. En effet, à la première et à la quatrième semaine, les GMQ les plus élevés ont été enregistrés chez les sujets nourris à la ration témoin, respectivement $74,8 \pm 1,40 \mathrm{~g} / \mathrm{j}$ et 62,4 $\pm 0,45 \mathrm{~g} / \mathrm{j}$; et les plus faibles chez ceux nourris à la ration contenant $30 \%$ Lagenaria siceraria, respectivement $12,9 \pm 0,88 \mathrm{~g} / \mathrm{j}$ et $16,9 \pm 1,16$ $\mathrm{g} / \mathrm{j}$. Par ailleurs, à la $2^{\text {ème }}$ et à la $3^{\text {ème }}$ semaine, les GMQ les plus élevés ont été obtenus chez les poulets alimentés à la ration témoin, respectivement $70,2 \pm 1,13 \mathrm{~g} / \mathrm{j}$ et $84,5 \pm 1,04$ $\mathrm{g} / \mathrm{j}$; et les plus faibles chez ceux nourris à la ration contenant $10 \%$ de Lagenaria siceraria et $10 \%$ de Citrullus lanatus (bebu), respectivement $9,76 \pm 0,18 \mathrm{~g} / \mathrm{j}$ et $8,81 \pm 0,16$ $\mathrm{g} / \mathrm{j}$.

Effets du tourteau des graines décortiquées du cultivar bebu de Citrullus lanatus et de Lagenaria siceraria sur l'indice de consommation (IC) des poulets de chair

Il ressort du Tableau 4 que, quel que soit l'âge, les IC des poulets ont été influencés de façon significative par la présence des tourteaux de cucurbites dans les rations. Cependant, ces IC ont été plus faibles chez les sujets nourris aux rations contenant les cucurbites que ceux obtenus chez les poulets 
soumis à la ration témoin. En effet, à la première, à la deuxième, à la troisième et à la quatrième semaine, les IC les plus faibles ont été enregistrés chez les animaux alimentés à la ration contenant $30 \%$ de Citrullus lanatus (bebu), respectivement $0,35 \pm 0,01 ; 0,71 \pm$ 0,$01 ; 1,07 \pm 0,02$ et $1,35 \pm 0,01$; et les plus élevés chez ceux nourris à la ration témoin, respectivement $1,47 \pm 0,02 ; 2,67 \pm 0,01 ; 4,11$ $\pm 0,01$ et $4,44 \pm 0,01$.

Effets du tourteau des graines décortiquées du cultivar bebu de Citrullus lanatus et de Lagenaria siceraria sur le taux de mortalité des poulets de chair

Le Tableau 5 indique que la mortalité était enregistrée à la première semaine avec les rations contenant les cucurbites et à la quatrième semaine avec la ration témoin et celles contenant les cucurbites. En effet, bien que la mortalité soit faible, elle a été enregistrée chez les poulets nourris à la ration contenant $10 \%$ de Lagenaria siceraria, soit un taux de mortalité de 5\% et chez ceux soumis à la ration contenant $20 \%$ de Lagenaria siceraria, soit un taux de $2,5 \%$.

Effet du tourteau des graines décortiquées du cultivar bebu de Citrullus lanatus et de Lagenaria siceraria sur les paramètres biochimiques sanguins des poulets de chair

Du Tableau 6, il ressort que les rations alimentaires ont influencé les paramètres sanguins. En effet, l'analyse statistique révèle que les teneurs en glucose obtenues dans le sang des poulets nourris aux rations contenant $10 \%$; $20 \%$ et $30 \%$ de Lagenaria siceraria, respectivement $2,11 \pm 0,22 \mathrm{~g} / 1 ; 2,06 \pm 0,20 \mathrm{~g}$ / L et 2,09 $\pm 0,03 \mathrm{~g} / \mathrm{L}$ ont été comparables ( $p$ $>0,05)$ entre elles et statiquement plus élevées $(p<0,05)$ que celle obtenue chez les sujets contenant $10 \%$ de bebu de Citrullus lanatus dans leur ration $(1,6 \pm 0,08 \mathrm{~g} / \mathrm{L})$, mais comparables $(p>0,05)$ à celles enregistrées chez les poulets. Les teneurs en créatinine obtenues chez les sujets alimentés à la ration témoin $(5,50 \pm 0,50 \mathrm{mg} / \mathrm{L})$; aux rations contenant $10 \%$ de bebu de Citrullus lanatus $(4,50 \pm 0,50 \mathrm{mg} / \mathrm{L}) ; 10 \%$ de Lagenaria siceraria $(4,50 \pm 0,50 \mathrm{mg} / \mathrm{L})$ et $20 \%$ de
Lagenaria siceraria $(4,05 \pm 0,05 \mathrm{mg} / \mathrm{L})$ ont été comparables $(p>0,05)$ entre elles et statistiquement plus élevées $(p<0,05)$ que celles enregistrées chez les sujets nourris à $20 \%$ de bebu de Citrullus lanatus $(3,5 \pm 0,50 \mathrm{mg} /$ L) ; à 30\% de bebu de Citrullus lanatus (3,5 \pm $1,50 \mathrm{mg} / \mathrm{L}$ ) et à $30 \%$ de Lagenaria siceraria (3,50 $\pm 0,50 \mathrm{mg} / \mathrm{L})$. Par ailleurs, les teneurs en cholestérol obtenues chez les poulets alimentés à la ration contenant $30 \%$ de bebu de Citrullus lanatus $(1,44 \pm 0,01 \mathrm{~g} / \mathrm{L})$ et $30 \%$ de Lagenaria siceraria $(1,40 \pm 0,05 \mathrm{~g} / \mathrm{L})$ ont été comparables $(p>0,05)$ entre elles et statistiquement plus élevée que celle obtenue chez les poulets soumis à la ration contenant $10 \%$ de bebu de Citrullus lanatus $(1,02 \pm 0,06$ $\mathrm{g} / \mathrm{L})$; mais comparables $(p>0,05)$ à celles enregistrées chez les poulets nourris aux rations contenant $20 \%$ de bebu de Citrullus lanatus $(1,29 \pm 0,09 \mathrm{~g} / \mathrm{L}) ; 10 \%$ de Lagenaria siceraria $(1,11 \pm 0,02 \mathrm{~g} / \mathrm{L}) ; 20 \% \mathrm{de}$ Lagenaria siceraria $(1,21 \pm 0,12 \mathrm{~g} / \mathrm{L})$ et à la ration témoin $(1,08 \pm 0,06 \mathrm{~g} / \mathrm{L})$. S'agissant de triglycérides, la teneur obtenue chez les sujets nourris à 30\% de Lagenaria siceraria a été plus élevée $(p<0,05)$ que celles enregistrées chez ceux soumis aux rations contenant $10 \%$ de bebu de Citrullus lanatus et $20 \%$ de Lagenaria siceraria ; mais comparables $(p>0,05)$ à celles obtenues chez les sujets alimentés aux rations contenant $20 \%$ et $30 \%$ de bebu de Citrullus lanatus ; 10\% de Lagenaria siceraria et à la ration témoin. La teneur en acide urique enregistrée chez les sujets nourris à la ration témoin a été plus élevée $(p<0,05)$ que celle obtenue chez les animaux ayant le tourteau de cucurbite dans leurs rations. Les teneurs en protéines obtenues chez les sujets nourris à $30 \%$ de Lagenaria siceraria; à $20 \%$ et à $30 \%$ de bebu de Citrullus lanatus et à la ration témoin ont été statistiquement plus élevées ( $p$ $<0,05)$ que celles enregistrées chez les animaux soumis à la ration contenant $10 \%$ de bebu de Citrullus lanatus, mais comparables à celles obtenues chez les poulets alimentés aux rations contenant $10 \%$ et $20 \%$ de Lagenaria siceraria. 
Tableau 2 : Consommation alimentaire (CA) moyenne ( $\mathrm{g}$ ) en fonction des rations alimentaires et de l'âge des poulets.

\begin{tabular}{|c|c|c|c|c|c|c|c|c|c|c|}
\hline \multirow{3}{*}{$\begin{array}{l}\text { Age des } \\
\text { poulets } \\
\text { (jours) }\end{array}$} & & \multirow{3}{*}{$\begin{array}{c}\text { BT0 } \\
\text { (témoin) }\end{array}$} & \multicolumn{7}{|c|}{ Rations alimentaires } & \multirow[t]{2}{*}{ Statistique } \\
\hline & & & \multicolumn{3}{|c|}{ Citrullus lanatus (bebu) } & \multicolumn{4}{|c|}{ Lagenaria siceraria } & \\
\hline & & & $\begin{array}{l}\text { BT1Cl } \\
(10 \%)\end{array}$ & $\begin{array}{l}\text { BT2Cl } \\
(20 \%)\end{array}$ & $\begin{array}{l}\text { BT3Cl } \\
(30 \%)\end{array}$ & $\begin{array}{l}\text { BT1Ls } \\
(10 \%)\end{array}$ & $\begin{array}{l}\text { BT2Ls } \\
(20 \%)\end{array}$ & $\begin{array}{l}\text { BT3Ls } \\
\text { (30\%) }\end{array}$ & $\boldsymbol{F}$ & $P$ \\
\hline 14-21 & CA & $\begin{array}{r}749 \pm \\
1,25^{\mathrm{a}}\end{array}$ & $\begin{array}{r}434 \pm \\
2,77^{\mathrm{b}}\end{array}$ & $\begin{array}{l}371 \pm \\
2,31^{\mathrm{d}}\end{array}$ & $\begin{array}{r}178 \pm \\
1,50^{\mathrm{f}}\end{array}$ & $\begin{array}{l}411 \pm \\
2,99 \mathrm{c}\end{array}$ & $\begin{array}{l}415 \pm \\
2,59 \mathrm{c}\end{array}$ & $\begin{array}{l}346 \pm \\
2,13^{\mathrm{e}}\end{array}$ & 261 & $<0,001$ \\
\hline $22-28$ & CA & $\begin{array}{r}865 \pm \\
2,38^{\mathrm{a}}\end{array}$ & $\begin{array}{r}333 \pm \\
1,78^{\mathrm{b}}\end{array}$ & $\begin{array}{r}281 \pm \\
1,76^{\mathrm{e}}\end{array}$ & $\begin{array}{r}250 \pm \\
1,31^{\mathrm{g}}\end{array}$ & $\begin{array}{r}323 \pm \\
1,56^{\mathrm{c}}\end{array}$ & $\begin{array}{l}303 \pm \\
1,47^{\mathrm{d}}\end{array}$ & $\begin{array}{l}275 \pm \\
1,61^{\mathrm{f}}\end{array}$ & 184 & $<0,001$ \\
\hline 29-35 & CA & $\begin{array}{r}1128 \pm \\
3,45^{\mathrm{a}}\end{array}$ & $\begin{array}{r}341 \pm \\
2,85^{\mathrm{c}}\end{array}$ & $\begin{array}{r}310 \pm \\
2,49^{\mathrm{e}}\end{array}$ & $\begin{array}{r}283 \pm \\
1,28^{\mathrm{g}}\end{array}$ & $\begin{array}{r}377 \pm \\
1,77^{\mathrm{b}}\end{array}$ & $\begin{array}{r}319 \\
\pm 1,53^{\mathrm{d}}\end{array}$ & $\begin{array}{l}306 \pm \\
2,87^{\mathrm{e}}\end{array}$ & $\begin{array}{c}142 \\
3\end{array}$ & $<0,001$ \\
\hline $36-42$ & CA & $\begin{array}{r}1107 \pm \\
2,29^{\mathrm{a}}\end{array}$ & $\begin{array}{r}430 \pm \\
1,34^{\mathrm{d}}\end{array}$ & $\begin{array}{r}435 \pm \\
1,99^{d}\end{array}$ & $\begin{array}{r}455 \pm \\
2,19^{c}\end{array}$ & $\begin{array}{c}471 \pm \\
2,49^{\mathrm{b}}\end{array}$ & $\begin{array}{r}440 \pm \\
2,07^{\mathrm{d}}\end{array}$ & $\begin{array}{l}451 \pm \\
1,92^{\mathrm{c}}\end{array}$ & 396 & $<0,001$ \\
\hline
\end{tabular}

A chaque âge des poulets (chaque ligne), les valeurs portant la même lettre sont statistiquement égales $(p \geq 0,05)$; CA : consommation alimentaire.

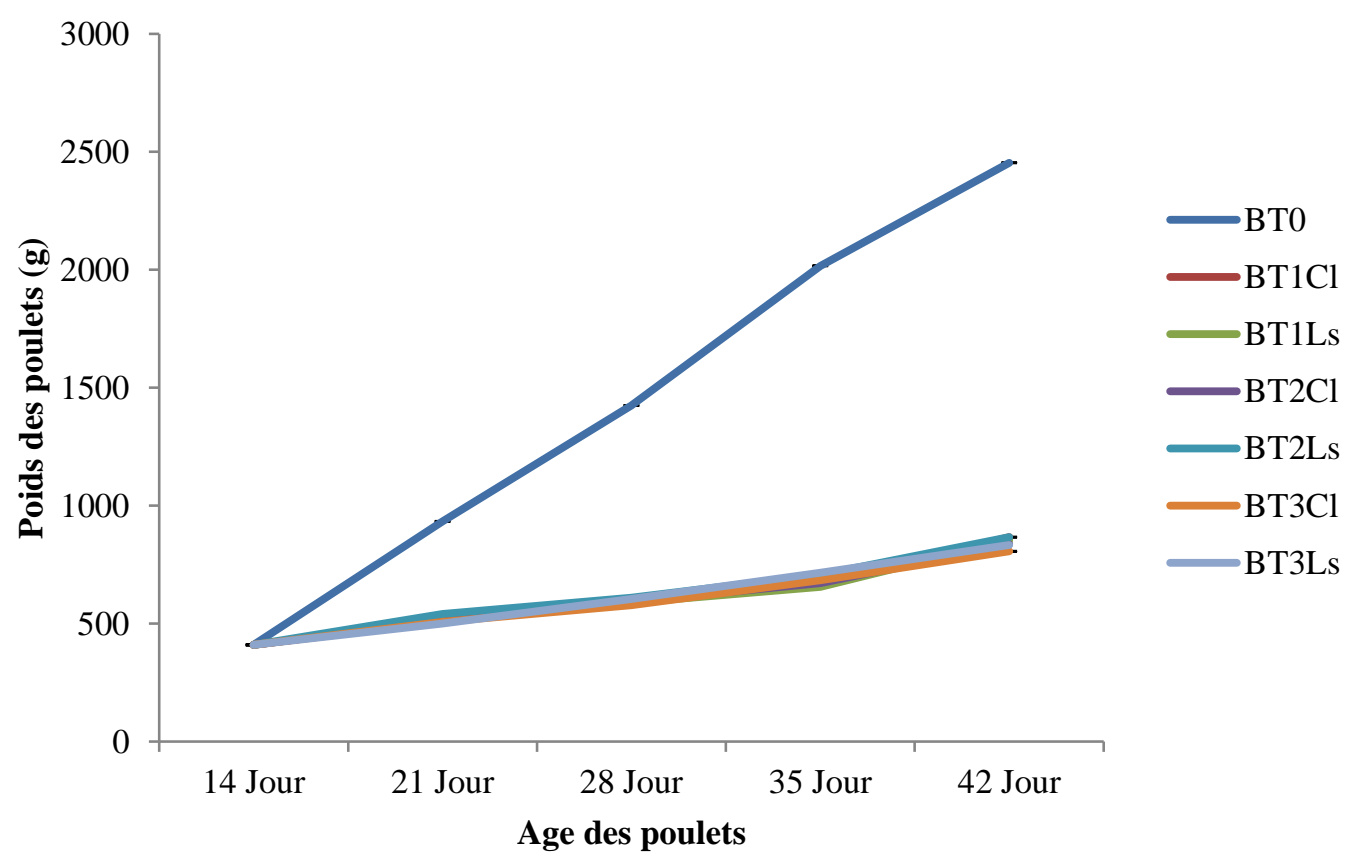

Figure 1: Evolution pondérale des poulets, du $14^{\text {ème }}$ au $42^{\text {ème }}$ jour d'âge, en fonction des rations alimentaires. 
Tableau 3 : Gain moyen quotidien (GMQ) en fonction des différentes rations alimentaires et de l'âge des poulets.

\begin{tabular}{|c|c|c|c|c|c|c|c|c|c|c|}
\hline \multirow{3}{*}{$\begin{array}{l}\text { Age } \\
\text { des } \\
\text { poulets } \\
\text { (jours) }\end{array}$} & & \multirow{3}{*}{$\begin{array}{c}\text { BT0 } \\
\text { (témoin) }\end{array}$} & \multicolumn{6}{|c|}{ Régimes alimentaires } & \multirow{3}{*}{$\boldsymbol{F}$} & \multirow[t]{3}{*}{$\boldsymbol{P}$} \\
\hline & & & \multicolumn{3}{|c|}{ Citrullus lanatus (bebu) } & \multicolumn{3}{|c|}{ Lagenaria siceraria } & & \\
\hline & & & $\begin{array}{l}\text { BT1Cl } \\
(10 \%)\end{array}$ & $\begin{array}{l}\text { BT2Cl } \\
(20 \%)\end{array}$ & $\begin{array}{l}\text { BT3CL } \\
(30 \%) \\
\end{array}$ & $\begin{array}{l}\text { BT1Ls } \\
(10 \%)\end{array}$ & $\begin{array}{l}\text { BT2Ls } \\
(20 \%)\end{array}$ & $\begin{array}{l}\text { BT3Ls } \\
(30 \%)\end{array}$ & & \\
\hline 14-21 & GMQ & $\begin{array}{c}74,8 \pm \\
1,40^{\mathrm{d}}\end{array}$ & $\begin{array}{l}14,3 \pm \\
0,69^{\mathrm{ab}}\end{array}$ & $\begin{array}{l}15,0 \pm \\
2,08^{\mathrm{b}}\end{array}$ & $\begin{array}{l}14,1 \pm \\
0,97^{\mathrm{ab}}\end{array}$ & $\begin{array}{c}18,8 \pm \\
0,87^{\mathrm{c}}\end{array}$ & $\begin{array}{l}13,8 \pm \\
0,69^{\mathrm{ab}}\end{array}$ & $\begin{array}{c}12,9 \pm \\
0,88^{\mathrm{a}}\end{array}$ & 2611 & $\begin{array}{c}< \\
0,001\end{array}$ \\
\hline $22-28$ & GMQ & $\begin{array}{c}70,2 \pm \\
1,13^{\mathrm{e}}\end{array}$ & $\begin{array}{c}13,6 \pm \\
0,44^{\mathrm{c}}\end{array}$ & $\begin{array}{c}10,5 \pm \\
0,42^{\mathrm{a}}\end{array}$ & $\begin{array}{c}12,1 \pm \\
0,75^{\mathrm{b}}\end{array}$ & $\begin{array}{c}9,76 \pm \\
0,18^{\mathrm{a}}\end{array}$ & $\begin{array}{c}10,2 \pm \\
0,53^{\mathrm{a}}\end{array}$ & $\begin{array}{c}15 \pm \\
0,67^{d}\end{array}$ & 8149 & $\begin{array}{c}< \\
0,001\end{array}$ \\
\hline 29-35 & GMQ & $\begin{array}{c}84,5 \pm \\
1,04^{\mathrm{e}}\end{array}$ & $\begin{array}{c}8,81 \pm \\
0,16^{\mathrm{a}}\end{array}$ & $\begin{array}{c}9,52 \pm \\
0,31^{\mathrm{a}}\end{array}$ & $\begin{array}{c}11,2 \\
\pm 0,24^{\mathrm{b}}\end{array}$ & $\begin{array}{r}13,8 \\
\pm 0,2^{\mathrm{c}}\end{array}$ & $\begin{array}{r}15,1 \pm \\
0,83^{d}\end{array}$ & $\begin{array}{r}15,7 \pm \\
0,87^{\mathrm{d}}\end{array}$ & 13420 & $\begin{array}{c}< \\
0,001\end{array}$ \\
\hline $36-42$ & GMQ & $\begin{array}{c}62,4 \pm \\
0,45^{\mathrm{d}}\end{array}$ & $\begin{array}{c}28,6 \pm \\
0,35^{\mathrm{c}}\end{array}$ & $\begin{array}{c}28,3 \pm \\
0,31^{\mathrm{c}}\end{array}$ & $\begin{array}{c}23,6 \pm \\
0,30^{\mathrm{b}}\end{array}$ & $\begin{array}{c}22,9 \pm \\
0,24^{\mathrm{b}}\end{array}$ & $\begin{array}{c}17,5 \pm \\
1,04^{\mathrm{a}}\end{array}$ & $\begin{array}{c}16,9 \pm \\
1,16^{\mathrm{a}}\end{array}$ & 3996 & $\begin{array}{c}< \\
0,001\end{array}$ \\
\hline
\end{tabular}

A chaque âge des poulets (chaque ligne), les valeurs portant la même lettre sont statistiquement égales $(p \geq 0,05)$; GMQ: gain moyen quotidien.

Tableau 4 : Indice de consommation (IC) en fonction des rations alimentaires et de l'âge des poulets.

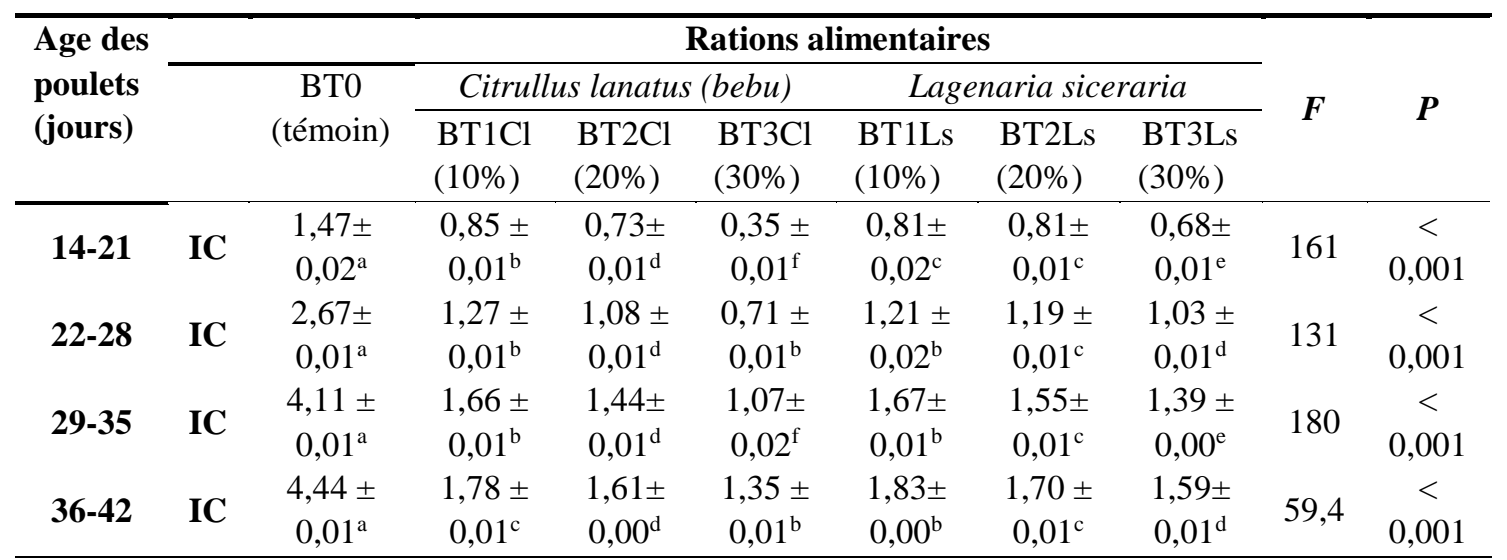

A chaque âge des poulets (chaque ligne), les valeurs portant la même lettre sont statistiquement égales $(p \geq 0,05)$; IC: indice de consommation.

Tableau 5 : Taux de mortalité (M) en fonction des rations alimentaires et de l'âge des poulets.

\begin{tabular}{ccccccccc}
\hline & \multicolumn{8}{c}{ Rations alimentaires } \\
\cline { 3 - 8 } $\begin{array}{c}\text { Age des poulets } \\
\text { (jours) }\end{array}$ & $\begin{array}{c}\text { BT0 } \\
\text { (témoin) }\end{array}$ & $\begin{array}{c}\text { Citrullus lanatus }(\text { bebu }) \\
\text { BT1Cl }\end{array}$ & BT2Cl & BT3Cl & BT1Ls & BT2Ls & BT3Ls \\
& & & $(\mathbf{1 0} \%)$ & $\mathbf{( 2 0} \%)$ & $\mathbf{( 3 0} \%)$ & $\mathbf{( 1 0} \%)$ & $(\mathbf{2 0} \%)$ & $(\mathbf{3 0} \%)$ \\
\hline $\mathbf{1 4 - 2 1}$ & M & 0 & 0 & 0 & 0 & 2 & 1 & 0 \\
$\mathbf{2 2 - 2 8}$ & M & 0 & 0 & 0 & 0 & 0 & 2 & 1 \\
$\mathbf{2 9 - 3 5}$ & M & 0 & 0 & 0 & 0 & 0 & 0 & 0 \\
$\mathbf{3 6 - 4 2}$ & M & 3 & 3 & 1 & 0 & 0 & 0 & 0 \\
\hline Total & & $3 / 40$ & $3 / 40$ & $1 / 40$ & $0 / 40$ & $2 / 40$ & $1 / 40$ & $1 / 40$ \\
\hline Pourcentage (\%) & 7,5 & 7,5 & 2,5 & 0 & 5 & 2,5 & 2,5 \\
\hline
\end{tabular}

A chaque âge des poulets (chaque ligne), les valeurs portant la même lettre sont statistiquement égales $(p \geq 0,05) ;$ M: mortalité. 
A. I. TOURE et al. /Int. J. Biol. Chem. Sci. 15(4): 1494-1510, 2021

Tableau 6 : Paramètres biochimiques du sang des poulets en fonction des différentes rations alimentaires.

\begin{tabular}{|c|c|c|c|c|c|c|c|c|c|}
\hline \multirow{3}{*}{ Paramètres } & \multicolumn{7}{|c|}{ Rations alimentaires } & \multirow{3}{*}{$F$} & \multirow{3}{*}{$P$} \\
\hline & \multirow{2}{*}{$\begin{array}{c}\text { BT0 } \\
\text { (témoin) }\end{array}$} & \multicolumn{3}{|c|}{ bebu de Citrullus lanatus } & \multicolumn{3}{|c|}{ Lagenaria siceraria } & & \\
\hline & & $\begin{array}{l}\text { BT1Cl } \\
(10 \%)\end{array}$ & $\begin{array}{l}\mathrm{BT} 2 \mathrm{Cl} \\
(20 \%)\end{array}$ & $\begin{array}{l}\text { BT3Cl } \\
(30 \%)\end{array}$ & $\begin{array}{l}\text { BT1Ls } \\
(10 \%)\end{array}$ & $\begin{array}{l}\text { BT2Ls } \\
(20 \%)\end{array}$ & $\begin{array}{l}\text { BT3Ls } \\
(30 \%)\end{array}$ & & \\
\hline Glucose (g/1) & $1,92 \pm 0,01^{\mathrm{ab}}$ & $1,60 \pm 0,08^{b}$ & $1,82 \pm 0,05^{\mathrm{ab}}$ & $1,84 \pm 0,01^{\mathrm{ab}}$ & $2,11 \pm 0,22^{\mathrm{a}}$ & $2,06 \pm 0,20^{a}$ & $2,09 \pm 0,03^{\mathrm{a}}$ & 1881 & $<0,001$ \\
\hline Créatinine (mg / 1) & $5,50 \pm 0,50^{\mathrm{a}}$ & $4,50 \pm 0,50^{\mathrm{a}}$ & $3,50 \pm 0,50^{b}$ & $3,50 \pm 1,50^{b}$ & $4,50 \pm 0,50^{\mathrm{a}}$ & $4,05 \pm 0,05^{\mathrm{a}}$ & $3,50 \pm 0,50^{\mathrm{b}}$ & 240 & $\begin{array}{l}<0,001 \\
<0,001\end{array}$ \\
\hline Cholestérol (g / l) & $1,08 \pm 0,06^{\mathrm{ab}}$ & $1,02 \pm 0,06^{\mathrm{b}}$ & $1,29 \pm 0,09^{\mathrm{ab}}$ & $1,44 \pm 0,01^{\mathrm{a}}$ & $1,11 \pm 0,02^{\mathrm{ab}}$ & $1,21 \pm 0,12^{\mathrm{ab}}$ & $1,40 \pm 0,05^{\mathrm{a}}$ & 2490 & $<0,001$ \\
\hline Triglycérides (g / l) & $0,52 \pm 0,02^{a b}$ & $0,40 \pm 0,06^{b}$ & $0,44 \pm 0,09^{a b}$ & $0,50 \pm 0,12^{\mathrm{ab}}$ & $0,42 \pm 0,02^{\mathrm{ab}}$ & $0,44 \pm 0,01^{b}$ & $0,68 \pm 0,12^{\mathrm{a}}$ & 313 & $<0,001$ \\
\hline Acide urique $(\mathrm{mg} / \mathrm{l})$ & $102 \pm 25,0^{\mathrm{a}}$ & $46,5 \pm 32,5^{\mathrm{e}}$ & $74,5 \pm 15,5^{\mathrm{c}}$ & $81,0 \pm 2,00^{b}$ & $47,5 \pm 25,5^{\mathrm{e}}$ & $66,0 \pm 8,00^{\mathrm{d}}$ & $71,5 \pm 5,50^{\mathrm{c}}$ & 89,6 & $<0,001$ \\
\hline Protéines (g / 1) & $40,5 \pm 0,50^{\mathrm{a}}$ & $28,5 \pm 1,50^{\mathrm{b}}$ & $39,5 \pm 1,50^{\mathrm{a}}$ & $39,0 \pm 1,00^{\mathrm{a}}$ & $36,0 \pm 6,00^{\mathrm{ab}}$ & $36,0 \pm 2,00^{\mathrm{ab}}$ & $40,5 \pm 1,50^{\mathrm{a}}$ & 1408 & \\
\hline
\end{tabular}

A chaque ligne, les valeurs portant la même lettre sont statistiquement égales ( $p \geq 0,05)$. 


\section{DISCUSSION}

\section{Effets du tourteau des graines décortiquées du cultivar bebu de Citrullus lanatus et de Lagenaria siceraria sur la croissance des poulets de chair}

Les rations alimentaires ont présenté des effets significatifs sur la croissance des différents groupes de poulets de chair durant la présente étude. L'appétence des poulets augmente de façon notable avec leur âge. Diaw et al. (2012) avaient également rapporté un accroissement de la consommation alimentaire des poulets de chair Cobb 500 nourris d'aliments à base de tourteau d'arachide et à la fève de coton glandless. L'accroissement de la consommation alimentaire chez les poulets de chair Hubbard examinés dans la présente étude pourrait s'expliquer par le fait que leurs besoins physiologiques et métaboliques augmentent (Virden et Kidd, 2009). Selon Bouvarel et al. (2010), les nutriments absorbés permettent le métabolisme de base, la régulation de la température corporelle et les biosynthèses ainsi que les activités physiques de l'animal. Mais, cette consommation alimentaire dépend également des préférences de l'animal et de la connaissance qu'il a de l'aliment. Ainsi, malgré l'accroissement de la consommation alimentaire pour toutes les rations (BT0 et à 10, 20 et $30 \%$ du cultivar bebu de C. lanatus et Lagenaria siceraria), celles-ci ont été diversement appréciées par les oiseaux. La plus grande préférence a été portée sur l'aliment commercial (BT0) au détriment de ceux à base de tourteaux de Cucurbitaceae oléagineuses. Cette forte préférence pour l'aliment commercial pourrait s'expliquer par ses qualités organoleptiques. En effet, selon Aldrich et Koppel (2015), la prise alimentaire est gouvernée par différents facteurs successifs dont les premiers sont sensoriels (le goût, le toucher, l'odorat, la vue, etc.). La préférence pour l'aliment commercial s'expliquerait donc par une odeur plus agréable et un goût moins acide $(\mathrm{pH}=6,88)$ que les aliments à base de Cucurbitaceae $(\mathrm{pH}<6)$. L'indice de consommation (IC) a également été influencé par les différentes rations alimentaires. Globalement, les IC augmentent avec l'âge des poulets. Cependant, les IC issus des poulets nourris à l'aliment commercial (témoin) ont été plus élevés $(4,44 \pm 0,01)$ que ceux des poulets nourris à base de tourteau de Cucurbitaceae $(1,78 \pm 0,01$ et $1,83 \pm 0,00$ respectivement pour le cultivar bebu de $C$. lanatus et L.siceraria à $10 \%$ d'incorporation). Les indices de consommation des sujets nourris au régime à base de tourteau de Cucurbitaceae sont lourdement affectés avec des baisses de performances pondérales. Ces baisses de performances, avec les rations de tourteaux de Cucurbitaceae peuvent être dues à des carences en acides aminés essentiels notamment la lysine $(0,41-0,67)$ qui reste en deçà de la norme recommandée par Ebling et al. (2013) qui varie de 1,15 à $1,30 \mathrm{~g} / 100 \mathrm{~g}$ de MS d'aliment. En effet, la lysine exerce une action physiologique hématopoïétique en augmentant le taux d'hémoglobine et d'érythrocytes. Elle influence indirectement la croissance des jeunes oiseaux et favorise la pigmentation du plumage. Quant à la méthionine, elle joue un rôle très particulier dans la biosynthèse des protéines car toutes chaines protéiques démarrent par l'incorporation d'une méthionine en position $\mathrm{N}$-terminal. En d'autres termes, la valeur biologique d'un aliment évaluée sur la base de ses caractéristiques qualitatives dépend de la présence d'une quantité adéquate de méthionine (Nimni et al., 2007; Zhai et al., 2012). La haute valeur de l'indice de consommation (IC) obtenue avec l'aliment témoin pourrait s'expliquer par de bonnes qualités organoleptiques (odeur et goût). Toutefois, cet indice est resté trop élevé ; ce qui remet en cause les performances de cet aliment. La variation des rations alimentaires a également présenté un effet significatif sur la croissance à travers le poids vif des poulets. Ainsi, quel que soit le régime alimentaire considéré, le poids des poulets a connu une croissance progressive tout au long de l'élevage. Ce résultat signifie que toutes les rations alimentaires testées sur les poulets contiennent le minimum d'éléments nutritifs pour leur maintien en vie. La comparaison des poids vifs moyens des poulets issus des différentes rations alimentaires a indiqué que celles-ci ont différé significativement les uns 
des autres. Ainsi, la ration témoin (BT0) a induit la meilleure performance de ces paramètres. Cela s'expliquerait par un taux normal de protéines $(20,4 \%)$ avec un taux plus élevé de 1,21\% de Lysine, et moins de fibres (7,2\% MS). Selon Urban et al. (2018), le taux de protéines doit être compris entre 19,6 et $21,7 \%$ MS dans l'aliment pour les poulets de chair à croissance rapide. En effet, les protéines jouent divers rôles (plastique et métabolique) dans l'organisme, ce qui concourt à la croissance, au maintien et au bon fonctionnement de ce dernier (Qaïd et AlGaradi, 2021). Cependant, malgré le taux relativement élevé de protéines (environ 20\%) dans les rations à $30 \%$ d'incorporation des Cucurbitaceae (cultivar bebu de C. lanatus et L. siceraria), les performances pondérales des poulets exprimées à tra vers leur poids vif sont restées plus faibles que celles des poulets nourris à l'aliment témoin (BT0). Ces baisses de performances sont traduites aussi par une diminution de l'ingestion alimentaire chez tous les poulets nourris aux tourteaux de Cucurbitaceae. Plusieurs hypothèses pourraient expliquer ce résultat. Ce sont, entre autres, la présence de facteurs antinutritionnels et de fibres (Nworgu et al., 2007 ; Samtiya et al., 2020) et un faible taux d'acides aminés essentiels (Quentin et al., 2004) dans la ration. Concernant la présence de facteurs antinutritionnels, Nworgu et al. (2007) avaient observé que l'action de cuisson des feuilles de la citrouille cannelée et apportée comme supplément alimentaire aux poulets de chair, réduisait le taux d'acide phytique et de tanins dans leur ration. Selon ces chercheurs, la réduction de ces facteurs antinutritionnels a permis une bonne croissance des animaux. A propos de la seconde hypothèse, van der Van et al. (2011) ont rapporté que l'incorporation de fibres indigestibles telles que la cellulose et la pectine dans l'aliment de la volaille déprécie sa croissance. Ainsi, le taux relativement élevé de fibres dans l'aliment à base de tourteaux de Cucurbitaceae (environ 11\%) pourrait expliquer la faible performance des poulets nourris avec cette ration comparativement à ceux de la ration témoin $(7,5 \%)$. Quant à l'hypothèse relative à la faible teneur en acides aminés essentiels, plusieurs études ont montré que malgré un taux élevé de protéines dans l'aliment, celui-ci doit pouvoir contenir qualitativement et quantitativement un certain nombre d'acides aminés essentiels à la bonne croissance des animaux. Il s'agit notamment de la lysine, de la méthionine et de la cystéine considérées comme facteurs limitants de la production de la volaille (Garcia et al., 2005 ; Sofi et al., 2009 ; Saengkerdsub et al., 2013). Certains de ces acides aminés essentiels seraient absents ou présents en très faible quantité dans les aliments formulés à base de tourteaux de graines de deux Cucurbitaceae (C. lanatus et $L$. siceraria).

Les rations alimentaires à $20 \%$ du cultivar bebu de C. lanatus et à 10, 20, 30\% d'incorporation de $L$. siceraria ont induit respectivement des mortalités de 2,5, 5, 2,5 et $2,5 \%$. Ces pourcentages sont globalement tolérables car inférieurs ou égaux à 5\% (Saleque et al., 2003 ; Schwean-Lardner et al., 2013). Des résultats similaires ont été obtenus par Shazali et al. (2013) avec une incorporation de $5 ; 10 ; 15$ et $20 \%$ de farine de Citrullus lanatus délipidé. Cependant, la ration incorporée à $10 \%$ de C. lanatus et l'aliment témoin ont induit un pourcentage de mortalité plus élevé $(7,5 \%)$ à la quatrième semaine. Ceci pourrait être lié à la qualité des aliments en rapport à l'âge avancé des animaux.

\section{Effets du tourteau des graines décortiquées du cultivar bebu de Citrullus lanatus et de Lagenaria siceraria sur les paramètres sanguins des poulets de chair}

Parallèlement à la baisse du poids et de l'appétence des poulets, les paramètres sanguins que sont le cholestérol, les triglycérides, l'acide urique et les protéines des poulets ont augmenté avec le taux d'incorporation des Cucurbitaceae dans leur aliment. Cet accroissement des taux des paramètres sanguins pourrait s'expliquer par une accumulation des nutriments à la base de leur source ou synthèse lors de l'alimentation. De telles observations avaient été faites par Nijdam et al. (2006) et Dupont et al. (2008). Le glucose est une substance indispensable à la survie des homéothermes. Il est en continu 
requis en tant que source d'énergie et son taux doit être maintenu à des niveaux stables dans le plasma. Chez la volaille, selon Hochleithner (2013), les valeurs usuelles de la glycémie sont situées autour de $2 \mathrm{~g} / \mathrm{L}$. Ainsi, dans cette étude, la teneur en glucose de 1,6 à $2,11 \mathrm{~g} / \mathrm{L}$ enregistrée, est considérée comme normale. La cholestérolémie dans cette étude est comprise entre 1,02 et $1,44 \mathrm{~g} / \mathrm{L}$, cela montre une teneur normale du cholestérol dans le sang des poulets nourris aux aliments à base de tourteaux de graines de Cucurbitaceae. En effet, selon Oloruntola et al. (2016), les valeurs de la cholestérolémie doivent se situer autour de 0,52 et $1,52 \mathrm{~g} / \mathrm{L}$ chez le poulet de chair. Les tryglycérides sont des réserves très importantes d'énergie, provenant des graisses apportées par l'alimentation mais aussi de la synthèse hépatique. La tryglicéridémie des poulets étudiée est de 0,40 à $0,68 \mathrm{~g} / \mathrm{L}$. Selon Hochleithner (2013), la valeur usuelle se situe autour de 1,6 g / L. La protéinémie a été de 28,50 à 40,50 $\mathrm{g} / \mathrm{L}$ chez les poulets nourris aux tourteaux de graines de Cucurbitaceae. Ces valeurs révèlent que l'alimentation des poulets contient une quantité convenable de protéines. En effet, le taux de protéines sanguin chez la volaille admis est de $25-45 \mathrm{~g} / \mathrm{L}$ (Thrall et al., 2012). L'uricémie enregistrée des poulets nourris aux régimes incorporés de tourteaux de Cucurbitaceae oscille entre 46,50 et $81 \mathrm{mg} / \mathrm{L}$. Pour le témoin R0, la concentration sanguine en acide urique est de $102 \mathrm{mg} / \mathrm{L}$. Cette valeur est légèrement au-dessus de la valeur usuelle admise par Parpinella et al. (2018), variant de 30 à $100 \mathrm{mg} / \mathrm{L}$. Cela pourrait s'expliquer par une teneur élevée de protéines de la ration témoin $(20,4 \%)$ avec une faible teneur en fibres $(7,62 \%)$. Une hypouricémie chez les oiseaux est beaucoup moins commune, elle est le signe d'une malnutrition prolongée, par diminution de l'apport protéique (Klasing, 2013) ou d'une atteinte hépatique sévère avec diminution de la synthèse de l'acide urique par le foie (Hochleithner, 2013). La créatininémie enregistrée dans tous les lots de poulets varie de 3,5 à $5,5 \mathrm{mg} / \mathrm{L}$. Cette valeur est inférieure à la norme usuelle qui est comprise entre 9 et $18 \mathrm{mg}$ / L, préconisée par Hochleithner (2013) chez le poulet de chair. D'après ce même auteur, la production de la créatinine est relativement constante et est très peu affectée par le catabolisme des protéines alimentaires ou tissulaires.

\section{Conclusion}

L'étude de l'incorporation des Cucurbitaceae dans l'alimentation du poulet de chair a indiqué que les différentes rations formulées ont eu des effets significatifs sur les performances zootechniques des animaux. L'élevage relatif à l'alimentation des poulets de chair (Hubbard F15) à base de tourteau des graines décortiquées de Lagenaria siceraria et du cultivar bebu de $C$. lanatus a montré une faible croissance pondérale des animaux comparativement au témoin (aliment commercial). Bien que l'appétence des poulets a décru fortement avec le taux d'incorporation des Cucurbitaceae (10, 20 et 30\%), leurs poids vifs sont restés tous similaires. Les valeurs des paramètres sanguins respectent les normes biologiques admises d'une croissance normale de poulet d'élevage.

\section{CONFLITS D'INTERETS}

Les auteurs déclarent qu'ils n'ont aucun conflit d'intérêts.

\section{CONTRIBUTIONS DES AUTEURS}

AIT a conçu, mis en place la conception expérimentale, participé à la conduite des essais et rédigé le manuscrit ; GCZT a participé à la mise en place du design expérimental et à la conduite des essais ainsi qu'à la lecture critique du manuscrit ; AVM, FNM ont participé à la révision du manuscrit et à l'assistance scientifique ; TBSD a participé à l'assistance technique et scientifique du travail ainsi qu'à la lecture critique du manuscrit ; MK, HHT, BIAZ et BB ont coordonné et guidé la réalisation technique et scientifique des travaux.

\section{REMERCIEMENTS}

Nous remercions très sincèrement l'Université des Sciences et Techniques de Masuku (USTM) au Gabon, pour avoir mis à notre disposition les outils nécessaires pour la réalisation de cette étude. 


\section{REFERENCES}

Aldrich GC, Koppel K. 2015. Pet food palatability evaluation: A review of standard assay techniques and interpretation of results with a primary focus on limitations. Animals, 5: 43-55. DOI: $10.3390 / \mathrm{ani} / 5010043$.

AOAC. 1990. Official Methods of Analysis of the Associat ion of Official Analytical Chemists $\left(15^{\text {th }}\right.$ Edn). AOAC: Washington DC, USA.

Araujo LF, Junqueira OM, Araújo CSS, Faria DE, Andreotti MO. 2004. Different criteria of feed formulation for broilers aged 43 to 49 days. Brazilian Journal of Poultry Science, 6(1): 61-64. DOI: https://doi.org/10.1590/S1516635X2004000100008.

Aviagen. 2018. Guide d'élevage de poulet de chair Arbor Acres. www.aviagen.com.

Bölükbaşi ŞC, Erhan MK, Özkan A. 2006. Effect of dietary thyme oil and vitamin E on growth, lipid oxidation, meat fatty acid composition and serum lipoproteins of broilers. South African Journal of Animal Science, 36 (3): 189 - 196.

Bouafou KGM, Doukoure B, Konan BA, Amonkan KA, Katy-Coulibally S. 2011. Substitution of fish meal with dried maggots' meal in growing rats' diet: histological and histopathological consequences. Journal of Applied Biosciences, 48: 3279-3283.

Bouvarel I, Lessire M, Narcy A, Duval E, Grasteau S, Quinsac A, Peyronnet C, Tran G, Heuze V. 2014. Les sources de protéines dans l'alimentation du bétail. Des sources de protéines locales pour l'alimentation des volailles : quelles voies de progrès? Oilseeds \& Fats Crops and Lipids, 21(4): 1-6. DOI: https://doi.org/10.1051/ocl/2014014.

Brah N, Houndonougbo MF, Issa S. 2015. Etapes et méthodes de formulation d'aliment de volaille : Une synthèse bibliographique. Int. J. Biol. Chem. Sci., 9(6): 2924-2931. DOI: http://dx.doi.org/10.4314/ijbcs.v9i6.31

Dawkins MS, Donnelly CA, Jones TA. 2004. Chicken welfare is influenced more by housing conditions than by stocking density. Nature, 427: 432-344. DOI: 10.1038/nature02226

Diaw MT, Dieng A, Mergeai G, Camara A, Hornick JL. 2012. Effets de la substitution totale du tourteau d'arachide par la fève de coton glandless sur les performances zootechniques de poulets de chair au sénégal. Revue d'Elevage et de Médecine Vétérinaire des Pays Tropicaux, 65: 1-2. DOI : 10.19182/remvt.10128.

Dupont J, Tesseraud S, Derouet M, Collin A, Rideau N, Crochet S, Godet E, CailleauAudouin E, Metayer-Coustard S, Duclos MJ, Gespach C, Porter TE, Cogburn LA, Simon J. 2008. Insulin immunoneutralization in chicken: effects on insulin signaling and gene expression in liver and muscle. Journal of Endocrinology, 197: 531-542. DOI: $10.1677 / \mathrm{JOE}-08-0055$.

Ebling PD, Ribeiro AML, Trevizan L, Silva ICM, da Kessler A de M, Rubin LL. 2013. Effect of different dietary concentrations of amino acids on the performance of two different broiler strains. Brazilian Journal of Poultry Science, 15(4): 339 - 346. DOI: $\quad$ https://doi.org/10.1590/S1516635X2013000400008.

Garcia AFQ M, Murakami AE, Duarte CRA, Rojas ICO, Picoli KP, Puzotti MM. 2013. Use of vitamin $\mathrm{D}_{3}$ and its metabolites in Broiler chicken feed on performance, bone parameters and meat quality. Asian -Australasian Journal of Animal Science, 26(3): $\quad 408-415 . \quad$ DOI: https://doi.org/10.5713/ajas.2012.12455

Hochleithner M. 2013. Chapter 11: Biochemistries. In: Avian medicine online, by Harrison's bird foods: 223245.

www.avianmedicine.net/publication/cha pter11-biochemistries/ visité le 08/01/2016.

Jha R, Mishra P. 2021. Dietary fiber in poultry nutrition and their effects on nutrient utilization, performance, gut health, and environment: a review. Journal of Animal Science and Technology, 12(51). DOI: 
https://doi.org/10.1186/s40104-02100576-0.

Klasing KC. 2013. Nutritional diseases. In Book editor's David Eswagne. DOI: https://doi.org/10.1002/9781119421481. c429.

Mariotti F, Gardner CD. 2019. Dietary protein and amino acids in vegetarian diets: a review. Nutrients, 11(11): 26661. DOI: 103390/nu11112661.

Molina-Flores B, Manzano-Baena P, Coulibaly MD. 2020. The role of livestock in food security, poverty reduction and wealth creation in West Africa, Accra, Ghana. DOI: https://doi/10.4060/ca8385.

Niba AT, Meutchieye F, Fon D, Laisin AG, Taboh H, Njakoi H, Bela TA, Maass BL, Djikeng A, Manjeli Y. 2012. Current situation of cavy production in Cameroon: Challenges and opportunities. Livestock Research for Rural Development, 24, Article \#194. Retrieved March 17, 2013, from http://www.lrrd.org/lrrd24/11/niba24194. h.

Nijdam E, Lambooij E, Nabuurs MJ, Decuypere E, Stegeman JA. 2006. Influences of feeding conventional and semisynthetic diets and transport of broilers on weight gain, digestive tract mass, and plasma hormone and metabolite concentrations. Poultry Science, 85: 1652-1629. DOI: 10.1093/ps/85.9.1652.

Nimni ME, Han B, Cardoba F. 2007. Are we getting enough sulfur in our diet? Nutrition and Metabolism, 4(24). DOI: https://doi.org/10.1186/1743-7075-4-24.

Nworgu F. 2007. Economic importance and growth rate of broiler chickens served fluted pumpkin (Telfaria occidentalis) leaves extract. African Journal of Biotechnology, $\quad \mathbf{6}(2): \quad 167-174$. http://www.academicjournals.org/AJB

Oloruntola OD, Ayodele SO, Agbede JO, Oloruntola DA. 2016. Effect of feeding broilers chickens with diets containing Alchomea cordifolia leaf meal and enzyme supplementation. Archivos de Zootecnia, 65 (252): 489-498.
Oyelola BO, Otunola GA, Apata DF. 2004. Assessment of protein quality of processed melon seed as a component of poultry feed. Nigeria Society of Experimental. Biology, 16: 80-87. DOI: $10.4314 /$ biokem.v16i2.32572.

Parpinelli W, Cella PS, Savaris VDL, Nunes RV. 2018. Dry brewery residue in broiler chickens feed. Ciéncias Agrarias, 39(4) : 1707-1716.

DOI : https://doi.org/10.5433/16790359.v39n4p1707.

Qaïd MM, Al-Garadi MA. 2021. Protein and amino acids metabolism in poultry during and after heat stress: A review. Animals, 11(1167).

DOI: https://doi.org/10.3390/ani11041167.

Quentin M, Bouvarel I, Bastianelli D, Picard M. 2004. Quels besoins du poulet de chair en acides aminés essentiels? une analyse critique de leur détermination et de quelques outils pratiques de modélisation. INRA Productions Animales, 17(1): 9-34. DOI: 10.20870/productionsanimales.2004.17.1.3550.

Rahman AHMM. 2013. Systematic studies on Cucurbitaceae family at Rajshahi division, Bangladesh. Plant, 1(2): 10-15. DOI: 10.11648/j.plant.20130102.11

Ramachandran S, Singh SK, Larroche C, Soccol CR, Ashok PA. 2007. Oil cakes and their biotechnological applications A review. Bioresource Technology, 98: 2000-2009.

DOI: 10.1016/j.biortech.2006.08.002.

Saengkerdsub S, O’Bryan CA, Crandall1 PG, Steven C, Ricke SC. 2013. Possibility for probiotic sources of methionine for organic poultry nutritional supplementation: An Early Review. Journal of Probiotics \& Health, 1 (1): 2 7. DOI: $10.4172 / 2329-8901.1000103$.

Saleque MA, Rahman MH, Hossain MI. 2003. A retrospective analysis of chicken diseases diagnosed at the Brac poultry disease diagnostic centre of Gazipur. Bangladesh Journal of Veterinary 
Medecine, 1(1): 29-31. DOI: https://doi.org/10.3329/bjvm.v1i1.1914

Samtiya M, Aluko RE, Dhewa T. 2020. Plant food anti-nutritional factors and their reduction strategies: an overview. Food Production, Processing and Nutrition, 2(6).

DOI: https://doi.org/10.1186/s43014-0200020-5.

Schwean-Lardner K, Fancher BI, Gomis S, Van Kessel A, Dalal S, Classen H. 2013. Effect of day length on cause of mortality, leg health and ocular health in broilers. Journal of Poultry Science, 92: 1 - 11. DOI: 10.3382/ps.2011-01967.

Shazali HS, El-Zubeir EA, Abdelhadi OMA. 2013. The effects of feeding watermelon seed meal and full fat seed on broiler chicks growth. Iranian Journal of Applied Animal Science, 3(2): 279 - 282. https://www.sid.ir/en/journal/ViewPaper. aspx?id=323009.

Sodexam 2015 Données climatologiques de 2005 à 2015. Abidjan; Côte d'Ivoire.

Sofi PA, Wani SA, Rather AG, Wani SH. 2009. Review article: Quality protein maize (QPM): Genetic manipulation for the nutritional fortification of maize. Journal of Plant Breeding and Crop Science, 1(6): 244-253. DOI: https://doi.org/10.5897/JPBCS.9000113.

Steiner M, Nuno-Ameyaw P, Agbemafle I, Hammond S, Tano-Debrah K. 2014. Nutrient composition and protein quality of four spies of the Cucurbitaceae family. Advance Journal of Food and Technology, 6(8): 843-851. DOI: 10.19026/ajfst.6.122.

Syed QA, Akram M, Shukat R. 2019. Nutritional and therapeutic importance of the pumpkin seeds. Boimedical Journal of Scientific and Technical Research, 21: 15798-15803.

DOI:10.26717/BJSTR.2019.21.003586.

Thornton PK. 2010. Livestock production: recent trends, future prospects. Philosophical Transactions of the Royal Society B., 365: 2853-2867. DOI: htttps://doi.org/10.19182/rstb.2010.0137.

Thrall MA, Weiser G, Allison R, Campbell T. 2012. Clinical chemistry of commonnon domestic mammals, birds, reptiles, fish and amphibians. Veterinary Haematology and Clinical Chemistry, 2: 569-614.

Urban J, Röhe I, Zentek J. 2018. Effect of protein restriction on performance, nutrient digestibility and whole body composition of male Lohmann dual chickens. European Poultry Science, 82. DOI: 10.1399/eps.2018.221.

Van der Aar PJ, Fahey GC, Rike SCJr, Allen SE, Berger LL. 2011. Effects of dietary fiber on mineral status of chicks. The journal of Nutrition, 113: 653 - 661 . DOI: 10.1093/jn/113.3.653.

Virden WS, Kidd MT. 2009. Physiological stress in broilers: Ramifications on nutrient digestibility and responses. Journal of Applied Poultry Research, 18: $338 \quad-\quad 347 . \quad$ DOI: https://doi.org/10.3382/japr.2007-00093.

Zhai W, Araujo LF, Burgess SC, Cooksey AM, Pendarvis K, Mercier Y, Corzo A. 2012. Protein expression in pectoral skeletal muscle of chickens as influenced by dietary methionine. Poultry Science, 91: 2548 - 2555. DOI: 10.3382/ps.201202213. 